\title{
O SISTEMA PERSONALIZADO DE INSTRUÇĀO - UM RECURSO PARA A EDUCAÇÄO EM ENFERMAGEM *
}

\author{
Emilia Campos de Carvalho**
}

CARVALHO, E.C. de O sistema personalizado de instrução - um recurso para a educação em enfermagem. Rev. Esc. Enf. USP, São Paulo, 22(1)65-74, abr. 1988.

A autora enfatiza as caracteristicas e aplicaşōes do Método Keller, um método de ensino individual. Salienta a viabilidade de sua aplicação em Enfermagem, quer no ensino formal ou em educação continuada.

UNITERMOS: Educa̧̧ão em enfermagem. Métodos de ensino.

\section{INTRODUÇĀO}

Considerando a relevância da educação em Enfermagem e as condi. ções e necessidades de ensino envolvidas na educação continuada do pessoal de nível superior no Brasil, chega-se a indagar se o número de profissionais existentes e formados anualmente pelas escolas têm adequada oferta de cursos de pós-graduação, especialização, extensão universitária, jornadas, seminários e eventos similares, satisfazendo a demanda.

Outro aspecto que merece reflexão refere-se à abordagem dada, no ensino curricular, sobre a concepção de educação continuada, sua importância e forma de estimulação da mesma, nem sempre satisfatória. As dificuldades encontradas pelos enfermeiros, na busca ou manutenção de conhecimentos, somam-se a rotatividade dos turnos de serviços, a filosofia das instituiçôes empregadoras, que podem facilitar ou não a saída do profissional durante o horário de trabalho, o grau de autonomia do enfermeiro para definição de suas prioridades e as características da classe profissional e caracteristicas profissionais.

Ainda que alguns pontos levantados nesta problemática sejam relevantes, é necessário que os profissionais não se acomodem a esta situaçāo e criem condiçōes para que possam, segundo sua disponibilidade, realizar atividades que beneficiem tanto seu lado profissional quanto a sua pessoa como um todo.

Assim, as situaçōes conflitantes mencionadas, que parecem interferir no ritmo e tempo disponivel para a aprendizagem, poderão ser amenizadas pela utilização de ensino individualizado.

\footnotetext{
* Extraido da Tese de doutoramento apresentada ao Programa Interunidades da EERP/ EE-USP.

* Enfermeira. Professor-Assistente Doutor da Escola de Enfermagem de Ribeiråo Preto USP.
} 
Os profissionais de saúde enfrentam a necessidade de encontrar meios eficientes de absorver o crescente volume de conhecimentos biomédicos. Na opinião de GOULD (1982), professores e alunos devem ser incentivados a experimentar abordagens inovadoras à aprendizagem cognitiva e reconhecerem ao mesmo tempo a precisão de dar mais enfa. se ao desenvolvimento de habilidades. A instrução individual conduziria a este fim.

A instrução individualizada tem crescido a partir das idéias de Skinner que, juntamente com outros psicólogos, na década de 30, apresentaram o modelo de Análise Experimental do Comportamento, possibilitando aplicar no ensino, assim como em outras situaçōes naturais, os princípios estabelecidos nos laboratórios (WITTER 1973), levando a ampliar sistematicamente os conhecimentos sobre aquisição, manutenção e modificação do comportamento.

As propostas skinnerianas de análiese do comportamento notabilizaram-se por apresentar um arranjo de características que o tornam peculiar, permitindo seu emprego através da máquina de ensinar.

Nesta tecnologia é fundamental que o ambiente possa ser arranjado de tal forma que possibilite o aumento da "performance" do estudante, sem que haja dependência de controle aversivo. Para tanto, os materiais são apresentados parceladamente ao aluno, segundo seu grau de complexidade e as respostas com êxito são seguidas de reforço. Esta tecnologia inclui, também, a idéia de que o aluno é ativo e não passivo (SKINNER, 1972).

A partir das idéias deste autor, várias formas de Instrução Personalizada têm sido mencionadas, bem como suas relaçōes com outros sistemas instrucionais individuais e não individuais têm sido objeto de pesquisa.

RUSKIN \& RUSKIN (1977) mencionam que a Instrução personalizada aparece de várias formas, sendo as mais comumente empregadas a Instrução Programada (PI), Instrução Assistida por Computador (CAI), Instrução Prescrita Individualmente (IPI), Manejo de Contingência (CM), Audio-Tutorial (AT), Ensino de Precisão (PT) e Sisłema Personalizado de Instrução (PSI).

A instrução individual foi também objeto de estudo de ROSA (1976); em sua disertação de mestrado o autor apresenta uma visão histórica dos métodos individuais e salienta: o audio-tutorial de Postelwait, que visa a dar maior ênfase à aprendizagem que ao ensino propriamente dito; o ensino centrado no aluno que se apoia em Rogers e consiste em enfatizar o repertório básico do aluno e posteriormente apresentar-lhe condiçōes de ampliá-los através de técnicas estruturadas; o sistema de pacotes de instrução ou ensino através de módulos; e o plano Keller.

No presente trabalho optou-se, dentre os métodos individuais, pelo método Keller, sobre o qual serão feitas algumas consideraçōes e relatadas aplicações. 


\section{O PLANO KELLER}

Foi desenvolvido no início dos anos 60; também contém os principios da teoria da aprendizagem, como a maioria dos métodos personalizados.

A tecnologia de ensino denominada método Keller foi também chamada Sistema Keller de Ensino, Sistema de Passos ou Sistema de lnstrução (SPI ou PSI). Referindo-se à sua importância, RUSKIN (1977) menciona que, durante aproximadamente uma década (1960-1970), mais de 1000 artigos sobre o artigo foram publicados, possibilitando afirmar-se que nenhum método instrucional mereceu tanta investigação.

Por ser bastante difundido, far-se-á aqui suscinta referência histórica, suas vantagens, características e aplicaçōes * em geral e em específico em Enfermagem.

A origem desta tecnologia de ensino baseia-se em alguns aspectos relevantes para a aprendizagem, conhecidos na literatura e mencionada pelo próprio KELLER (1983 b) durante a Reunião Anual de Psicologia em Ribeirão Preto, SP, em $1983^{* *}$. Segundo ele, na $2^{\mathrm{a}}$ Guerra Mundıal, durante sua atuação militar, observou que o tratamento nesta área era individualizado e cada aprendiz tinha um ritmo próprio de aprendizagem, graduado. Pensou então utilizar as noçōes teóricas do reforço, com outros sujeitos na área educacional.

Com a vinda de Keller para o Brasil, em 1961, iniciaram-se em São Paulo os primeiros passos para a proposição do sistema de ensino por ele idealizado; no ano seguinte, com a criação do Departamento de Psicologia da Universidade de Brasília, surgiram novas perspectivas do uso da teoria do reforço.

Posteriormente, em 1963, Keller realizou um projeto piloto na Universidade de Columbia, New York EEUU, para alunos matriculados em curso de férias. Os alunos receberam instruções sobre o método, as atividades práticas e teóricas que cumpririam individualmente e, no final, consideraram o curso positivo, salientando a necessidade de mais discussões (BEGA, 1980).

A pesquisa básica completa desta tecnologia foi desenvolvida em Brasilia no ano seguinte, com 50 alunos de um curso introdutório de Psicologia. A avaliação deste curso fol julgada excelente pelos que o completaram.

Concomitante à experiência brasileira, em 1965, Sherman e Keller desenvolveram várias aplicações na Universidade do Estado do Arizona, EEUU, (KELLER, 1977).

* Uma revisăo histórica da origem e aplicaça do SPI pode ser encontrada em trabalhos de KELLER, 1967, 1968, 1973, 1976, 1983(a), KELLER \& SHERMAN (1974), SHERMAN (1974, 1977), BORI (1974) e BEGA (1980).

- Fista conferéncla apresentou um apanhado da obra Pedagogue's Progress publicada em 1982, traduztda por R, Azzl e M.T.A. Silva. 
Apesar do desenvolvimento simultâneo do SPI nos Estados Unidos e no Brasil, observaram-se características diversas, como menciona BORI (1974), uma das introdutoras deste método no Brasil. As dificuldades observadas neste País referem-se à infra-estrutura: falta de equipamento, de monitores, de verbas, o fato de os próprios docentes corrigirem as verificações dos passos, interesse centrado no conteúdo teórico do curso em detrimento do método propriamente dito e outros.

Posteriormente, em 1972, o plano Keller foi implantado no Instituto Tecnológico de Estudos de Monterrei, no México, constatando-se que era uma inovação no ensino, que apresentava alta probabilidade de exito dos alunos contrapondo-se aos métodos convencionais em muitos pontos. Uma das razões deste êxito é por estar centrado no fato de propiciar ao aluno atendimento pessoal e tutorial, com programação orientada para a perfeição auto-promamada e respeitando sua individualidade (KELLER, 1972-1968).

KELLER (1972) salienta, ao descrever esse método, as seguintes caracteristicas: requisito de perfeição em cada unidade para poder prosseguir, de forma que o aluno só tenha permissão para avançar quando já demonstrou domínio completo do capitulo precedente; o uso de palestras e demonstrações como veículo de motivação ao invés de fonte de informação, uso de monitores, o que permite a repetição de testes, avaliação imediata, tutela e acentuada ènfase no aspecto sócio-pessoal do processo educacional, e ênfase dada ao comportamento escrito nas comunicações entre professores e alunos. Keller ressalta, ainda, que as contigências reforçadoras devem ser cuiđadosamente planejadas, e os comportamentos finais, previamente estabelecidos, devem ser alcançados por todos alunos ao concluirem o curso, sendo desempenho final da classe de alto nível, em sua maioria (WITTER, 1975).

Outra caracteristica abordada por KELLER (1972) diz respeito ao encadeamento das respostas em cada unidade, bem como entre uma unidade e outra, respeitando-se sempre o grau de complexidade crescente nas unidades.

Uma ampla revisão é apresentada por RUSKIN \& RUSKIN (1977); nesta apresentam opiniões de outros autores sobre os componentes do SPI. Para estes autores, os componentes citados são: materiais escritos, desempenho correto, estudo objetivo, unidades pequenas, uso de instrutor e de leituras. Salientam que o mais efetivo, quando visto isoladamente, refere-se ao uso de pequenas unidades conjugadas a avaliaçóes, objetivos claramente definidos e desempenho especifico.

Vários estudos experimentais já foram realizados sobre o SPI, abordando os efeitos do acréscimos, e das alteraçōes, modificaçōes e análise extensiva dos seus componentes. Pode-se destacar os que foram realizados por Johnson \& Ruskin citados por RUSKIN \& RUSKIN (1977), Keller \& Sherman (1974) e Ruskín (1974), citado por RUSKIN \& RUSKIN (1977). 
De modo geral, tais caracteristicas podem ser sintetizadas, com respeito ao ritmo do aluno; uso de pequenas unidades; comunicação escrita; uso de monitores; exigência de perfeiçāo por unidade e ainda aumento da motivação através de palestras ou demonstração.

Este método de ensino tem sido aplicado a vários níveis de educaçāo. Uma série de artigos publicados no número especial do "Educational Tecnology" sobre SPI em 1977, contém ampla revisão bibliográfica de pesquisas aplicadas ao ensino superior, segundo grau e educação elementar nos EEUU.

Uma seleção de artigos sobre o planos Keller, nos EEUU, publicada por SHERMAN (1974), ressalta que este método inicialmente pesquisado em situações de ensino de Psicologia expandiu-se para outros campos como Física, Eletricidade, Engenharia Mecânica, Matemática e Estatística, Química, Filosofia. Outros cursos também o utilizaram como Antropologia, Astronomia, Educação, Geologia, História, Linguagem, Medicina, Mủsica, Religião, Sociologia, treinamento de enfermeiras e outros (KELLER, 1977).

KULIK \& JAKSA (1977) mencionam que nos últimos dez anos de pesquisas educacionais nos EEUU, o SPI, tem sido efetivo na programação estudantil nos cursos de terceiro grau, assim como outros. Tais métodos trazem melhor desempenho final e retenção mais duradoura, quando comparados ao tradicional. Esta efetividade está relacionada a avaliações freqüêntes, reforço imediato e exigências de dominio da unidade estudada.

No que concerne à utilização do SPI aplicado ao campo profissional, poucas experiências têm sido relatadas, segundo a opinião de SCHIMPFHAUSER \& RICHARDSON (1977), a área médica nos EEUU, o SPI tem sido empregado mais a nivel de graduação, do que de pós-graduação, exemplo disso é o trabalho que os autores efetuaram na programação de Bioquímica das escolas médicas, comparando o ensino tradicional com o SPI; concluiram que esta encontrou grande aceitação, demonstrando as várias vantagens por eles apontadas; salientam ainda que consideram esta metodologia útil para os outros cursos oferecidos tanto nas ciências básicas como nas clínicas.

Uma pesquisa abordando a efetividade do SPI, quando comparado a outras técnicas de ensino, tem mostrado sua superioridade em muitos aspectos, levando o aluno a dominar os conceitos ou habilidades motoras ensinadas (BORN; GLEDHILL; DAVIS, 1972).

HARTNETT (1966), ao comparar o desempenho de estudantes que freqüentavam curso onde eram empregados métodos tradicionais, com o de estudantes de igual capacidade submetidos a um programa de estudo individual, independente, verificou que, em $1 / 3$ do curso independente, os estudantes obtiveram média superior àqueles que assistiram aulas expositivas. Esses resultados corroboram a posição de SKINNER (1972), de que o método de ensino convencional não ensina, apenas seleciona os que aprendem sem terem sido ensinados. 
$\mathrm{Na}$ opinião de BEGA (1980), os métodos convencionais, além de manterem um prazo para o curso e não acompanharem o ritmo dos alunos, levando à reprovação os de grau diferente, medem sua qualidade de ensino através do comportamento do professor. No SPI o comportamento do aluno e a qualidade de sua aprendizagem é que vão servir como medida para a qualidade de ensino.

No Brasil muitas investigaçōes sobre o SPI têm demonstrado que: o desempenho na avaliação final é superior para alunos que freqüentaram este sistema de ensino individualizado; a retenção do material ensinado é superior em alunos do SPI; o tempo gasto em estudos é aproximadamente o mesmo em ambos os cursos; o relato verbal do aluno não deve ser o principal critério para o professor avaliar a eficiência dos diferentes procedimentos de ensino gue adota em sala de aula (ROSA, 1976).

As aplicações do SPI no Brasil, como lembra BEGA (1980), têm predominância no ensinc superior, nas disciplinas de vários cursos e abordam aspectos distintos.

No campo de Psicologia, o estudo proneiro de BORI; PESSOTI; AZZI (1965) cita os resultados obtidos e as dificuldades encontradas no desenvolvimento de programa sobre comportamento humano. Os resultados obtidos com os alunos que concluíram o curso quanto à avaliação experimental e teórica foram considerados suficientes para que a experiência fosse continuada.

Em 1969, WITTER \& ROSAMILHA fizeram uma pesquisa comparativa entre SPI e estudo convencional. Compararam a realização e as atitudes dos alunos que freqüentavam o curso programado, inclumndo unidades sob forma de instrução programada, com as de estudantes que assistiram a um curso sobre o mesmo conteúdo, ministrado pela professora sob forma de aulas expositivas. Os estudantes dos dois grupos submeteram-se a um teste de verificaçōes, o primeiro após cada passo, e o segundo após cada aula. A média de erros nos testes realizados após cada aula foi superior à dos testes realizados após cada passo, sendo também mais apreciadas as atividades do curso personalizado.

Verificando a influência da extensão das unidades no desempenho do estudante de um curso da disciplina Psicopatologia, ROSA (1976) comenta que os passos extensos têm efeitos indesejáveis no desempenho do aluno, e que os estudantes submetidos à experiência com os passos mais extensos consideram o SPI pior do que outros métodos de ensino; inverso foi observado com os estudantes submetidos a unidades de menor extensão.

Vários outros campos, além da Psicologia, utilizaram essa tecnologia de ensino. Na Engenharia, IDA; SANTORO; SEVA; FONSECA; SAITBY (1974) mencionam que o método foi iniciado no curso de graduação em Engenharia de produção da Escola Politécnica da USP, em 1969, da Escola de Engenharia da UFRJ, em 1972, e no curso de 
pòs-graduação em Engenharia da UFRJ em 1971. Salientam os autores que observaram, após aplicaçāo em dez cursos, vários beneficios tais como: programação dos estudos pelos próprios alunos, distribuição mais uniforme de carga de trabalho, maior aquisição de conhecimento, melhor capacidade de verbalização do aluno, avaliaçōes mais justas, melhor relacionamento professor-aluno e, finalmente, melhoria do ambiente social da classe.

No ensino de Eletricidade e Acústica para acadêmicos da Universidade de Mogi das Cruzes, SP, Weikoff \& Motejunas, citados por BEGA, (1980) foi obtido elevado índice de aprovação com a utilização do SPI; mencionam os autores que a interação professor-aluno obteve alto nivel e os alunos manifestaram ter sido o curso agradável.

Em outras áreas, como Biologia, NALE (1979), constatou a eficácia do método em face do índice de aprovação. Na área de Ciências Biomédicas, FRANCO \& SCHNEIDER (1979) utilizaram o SPI, tendo em vista a heterogeneidade inicial da classe; após avaliação do desempenho verificam a utilidade do sistema para superação das deficiências dos alunos decorrentes dos seus antecedentes sócio-culturais.

BEGA (1980) menciona resultados satisfatórios quanto ao aproveitamento, interesse dos alunos, e economia de tempo, quando é utilizado o SPI, como também, em trabalhos desenvolvidos fora do ambiente universitário, tais como em mecânica para funcionários de empresa e em técnicas agricolas.

Em seu estudo, esta autora verificou ser o treino de professores, através do SPI, eficiente para ser obtida melhoria no rítmo e rendimento acadêmico de alunos de primeira série do primeiro grau, com deficiência física.

Outras clientelas têm sido estudadas por outros autores. Quanto à utilização desta tecnologia por sujeitos adultos, ANDRADE (1979) menciona que ela desenvolve padrōes de comportamento típicos do adulto, podendo-se dizer ser ela adequada a este tipo de pessoas que usufruem das condiçōes de leitura.

\section{APLICAÇĀO DO SPI NA ENFERMAGEM}

No campo da Enfermagem já se observa a utilização desta tecnologia com sujeitos de vários níveis de escolarização, e não apenas com universitários. Destaca-se, como exemplo, o trabalho desenvolvido por Manzolli com auxiliares de enfermagem, em 1966, no ensino da Psicologia no curso de Auxiliar de Enfermagem.

Foi também verificada, na Enfermagem, a adequação do método às determinadas caracteristicas de trabalho na profissão. Pode-se citar o trabalho de VALLE (1982), que considerou ser útil este método de ensino no treinamento de enfermeiros pediatras, visando à recreação da 
criança hospitalizada, dada a escala de trabalho dos sujeitos, com rodízio de período; o método propriciou adequação do rítmo do aluno à sua disponibilidade de tempo. Além deste aspecto, conclui a autora, que o mesmo mostrou-se produtivo quanto às atividades desempenhadas, aos resultados obtidos nos testes de conhecimento e às atitudes favoráveis manifestadas quanto à sua avaliação.

Esta autora verificou, também, ser adequado o SPI, como metodologia, em recuperação escolar do primeiroanista de Enfermagem tendo obtido resultados positivos (VALLE, 1979).

Em recente estudo CARVALHO (1985) teve, como um de seus propósitos, conhecer aspectos do comportamento verbal do enfermeiro durante um procedimento técnico; após identificar falhas nesse comportamento a autora ofereceu às enfermeiras de duas clínicas, do hospital-escola em que desenvolveu o trabalho, um curso elaborado em SPI sobre "O diálogo enfermeiro-paciente instrumento de Educação em Enfermagem", após a realização do curso novamente observou a interação verbal enfermeiro-paciente.

Comparando-se os dados obtidos nas duas fases de observação, estes revelaram diferenças significantes, podendo-se afirmar ter havido adequação dessa metodologia de ensino ao trabalho com a clientela de enfermeiros nas condiçōes realizadas.

No quotidiano há casos inúmeros de aplicação do método que não foram publicados. É exemplo a sua utilização, pela presente autora, no ensino da unidade "Assistência de Enfermagem à Pacientes Portadores de Transtornos Hematológicos" da disciplina "Enfermagem Médica II" na Escola de Enfermagem de Ribeirão Preto, da USP, oferecida a alunos do sétimo semestre letivo. Esta programação, constando de passos, que inclui atividades teóricas, além de atividades práticas de ambulatório e junto a pacientes internados, tem obtido alto índice de aprovação e tem sido considerado útil pelos alunos, embora extensa, se comparada às demais atividades desenvolvidas no curso de Graduação.

No âmbito da Enfermagem o método tem-se mostrado adequado à educação continuada de enfermeiros e demais membros da equipe; a variedade de atribuiçōes que o pessoal de enfermagem exerce dificulta a realização de cursos tradicionais, com horários rígidos; este entrave pode ser contornado com o empregado do SPI, somando-se ainda o fato de que a inexistência de outros estímulos aversivos educacionais aumenta a eficiência do referido método.

CARVALHO, E.C. de The personalistic instruction system: an expedient for education in nursing. Rev. Esc. Enf. USP, Săo Paulo, 22(1):65-74, Apr. 1988.

The author emphasizes the characteristics and application of the Keller Method, $a$ individualized instruction methad. Highlights the feasiblititt for Nursing usage, either in formal or continued education.

UNITERMS: Nursing education. Teaching, methods. 


\section{REFERENCIAS BIBLIOGRAFICAS}

ANDRADE, M.B.S. Efeitos da instruçăo no SPI; realização e atitudes de universitários. Joåo Pessoa, 1979. (Dissertaçăo de Mestrado - Centro de Educação da Universidade Federal da Paraiba).

BEGA, R.C.B. Treinamento de professores para planejar e aplicar o SPI simultaneamente às suas atividades em classes de primeira sérle do primeiro grau com crianças fisicamente deficientes. Säo Paulo, 1980. (Dissertação de mestrado - Pontificia Universidade Cató. lica de Săo Paulo).

BORI, C.M.; PESSOTI, I.; AZZI, R. Um curso moderno de psicologla. Ci. e Cult., Săo Paulo, $17(2): 218,1965$.

BORI, C.M. Developments in Brazil. In: KELLER, F.S. \& SHERMAN, J.G. The Keller plan handbook. Menlo Park, W.A. Benjamin, 1974. p. 65-73.

BORN, D.G.; GLEDHILI, S.M.; DAVIS, M.L. Examination performance in lecture discussion and personalized instruction courses. J. Appl. Behav, Anal., Lawrence, 5:33-43, 1972.

CARVALHO, E.C. Comportamento verbal onfermeiro-paciente: funça educativa e educacão continuidada do profissional. Rubeirão Preto, 1985. (Tese de doutoramento - Escola de Enfermagem de Ribeirão Preto da USP).

FRANCO, J. \& SCHNEIDER, D. Aplicação do método Keller na área de ciéncias biomédicas com participação dos alunos no planejamento. Ci. Cult., São Paulo, 31(supl. 7):113-4, jul. 1979.

GOULD, B. Cognitive learning in the health sciences: a case for self instruction. Educ. Med. Salud, Washington, 16(2):174-82, 1982.

HARTNETT, R.T. Final examination grades of independent study students compared with those of students taught by tradicional methods. J. Educ. Res., 59(6):356-7, 1966.

IDA, I.; SANTORO, M.C.; SEVA, A.O.; FONSECA, R.S.; SALIBY, E. Aplicaç̃o do método do ensino individualtzado em engenharia. Ci. o Cult., Săo Paulo, 26(supl. 7):6-23, abr. 1974.

KELLFR, F.S. Neglected rewards in the educational process. In: AMERICAN CONFERENCE OF ACADEMICS DEANS, 23, Los Angeles, 1967. Procedinge. Los Angeles, 1967.

«Good bye, teacher ...». J. Appl. Behav. Anal., Lawrence, 1(1):79-89, 1968.

-. Aprendixagem: teoria do reforco. Såo Paulo, Herder, 1972.

\& SHERMAN, J.G. The Koller plan handbook. Menlo Park, W.A. Benjamln, 1974.

On my «experience in Brasil», Bol. Paic., São Paulo, 24(69):105-10, 1975.

Summers and sabbaticals: selected papers on psychology and education. Illinois, Rescarch Press, 1977.

1983. (a)

Aprendendo a ensinar: memórias de um professor universitário. São Paulo, Edicon,

- Imagens da vida de um professor. Trabalho apresentado na REUNIAO ANUAL DE PSICOLOGIA, 13, Ribeirão Preto, 1983. (b)

KULIK, J.A. \& JAKSA, P. PSI and other educational technologies in college teaching. Educ. Techn., Saddle Brook, 17(9):12-19, 1977.

NALE, N. Análise de uma sequêncla de passos de um curgo programado individuallzado de blologia. Ci. e Cult., Så Paulo, 29(supl. 7):834-5, jul. 1979.

ROSA, J.T. Avaliação de um curso programado de psicologia: influencia do tamanho das unidades no desempenho dos estudantes. Săo Paulo, 1976. (Dissertacão de mestrado Instituto de Psicologia da Universidade de Sao Paulo). 
RUSKIN, R.S. The personslized aystem of instruction (P.S.I.). Educ., Techn., Baddle Brook, $17(9): 5,1977$.

\& RUSKIN, R.L. Personalized instruction and its relation to other instructional systems. Educ. Techn., Saddle Brook, $17(9): 5-11,1977$.

SCHIMPFHAUSER, F. \& RICHARDSON, K. Medical educational and personalized instruction. Educ. Techn., Saddle Brook, 14(9):31-6, 1977.

Sherman, J,G. Personalized eyatem of instruction: 41 rerminal paperi. Menlo Park, W.A. Benjamin, 1974. 56-60, 1977.

SKINNER, B.F. Tecnologia do ensino. Sto Paulo, Herder, 1972.260 p.

VALLE, E.R.M. Recuperacto escolar de primeiranistas de enfermagem na disciplina de paicologia através do slatema personallzado de ensino. Cl. Cult., săo Paulo, \$1(supl. 7):36, jul. 1979 .

- Educaçăo permanente de enfermeiras pediatras sobre aspectos psicologicos da recreação num modelo de pesquisa particlpativa. Ribelrăo Preto, 1982 . (Dissertaça de mestrado - Escola de Enfermagem de Ribeirăo Preto da Universidade de Săo Paulo).

WITTER, G.P. Um novo modelo de ensino: o ensino como ciencia. In: WITTER, G.P.; LOMONACO, J.F.B.; COPIT, M.S.; IIBERALESCO, A.J.; AMARANTI, E.M. A pslcolosia a aprendizagem em sala de aula. Campinas, Pontificia Universidade Católica, 1973. p. 1-27.

WITTER, G.P. Sistema personalizado de instrução. In:

Clência, ontino o aprondiratam. Sao Paulo, Alfa Omega, 1975. p. 159-85.

\& ROSAmilha, N. Estudo comparativo de dols métodos de ensino. Ci. - Cult.. Såo Paulo, 21(2):393-7, 1969.

Recebldo para publicaçăo em 21-01-87.

Aprovado para publicaçăo em 24-02-88. 